\title{
INFLUENCER COMMUNICATION ON THE SOCIAL NETWORK INSTAGRAM
}

\author{
a EVA KALINOVÁ, b ADÉLA NEUBERGOVÁ \\ ${ }^{a, b}$ Institute of Technology and Business in České Budějovice, \\ School of Expertness and Valuation, Okružní 517/10, 37001 \\ České Budějovice, Czech Republic \\ email: ${ }^{a}$ kalinova@mail.vstecb.cz, ${ }^{b} 26898 @ m a i l . v s t e c b . c z$
}

Abstract: The topic of influencers has been a widely used word in recent years. It is a person who, through social media networks, influences the target groups of their followers. The aim of this paper is to analyze the communication of selected influencers on the social platform Instagram. Using classification analysis, data on individual influencers are presented. For the sake of interesting results and the proof that the success of an influencer does not only depend on how many followers they have on their profile, the influencers were selected with the help of respondents who assessed them independently. The data were obtained on the social platform Instagram and subsequently processed on the basis of the last five contributions as of April 3, 2020. This work is focused mainly on the number of responses to influencers in the form of likes or comments, furthermore we also calculate what share of their contributions is from 2020, mainly due to the fact that influencers on Instagram started to become known mostly in that year. The statistics of individual Instagram profiles and their subsequent comparison with each other are presented. The results show that it does not entirely depend on how many followers an influencer has, but that it depends more on the quality and impact of individual posts.

Keywords: social networks, Instagram, influencer, Instagram posts, communication

\section{Introduction}

Social networks, which arose as a result of the rapid development of modern telecommunications and information technologies, can be considered a phenomenon of the information society. In a short time, there has been a quantitative and qualitative growth of social networks, which have become commonplace in our lives (Bessarab et al. 2021). Social networks have completely redesigned the way people communicate with each other. Most importantly, these platforms play a major role in providing greater influence (Abdullah, 2020). Young people have found an ideal space in social networks for obtaining and relaying information (Martínez-Sanz and Gónzález-Fernández, 2018; Nadániová and Das, 2020).

Instagram has seen a remarkable increase worldwide over the past five years (Marauri-Castillo et al. 2021). Instagram posts have a positive impact on news credibility, access to advertising, or purchase intent (Lee and Kim, 2020).

Social networks are associated with the emergence of new types of personalities called influencers, who share their current experiences and ideas and often promote brands. Developing and maintaining a large community of followers is one of the most important goals of influencers (Balaban et al. 2020).

Although influencer marketing has attracted increased interest from marketing researchers in recent years, relatively little is known about the content and strategy of influencing influencers (Tafesse and Wood, 2021).

The aim of the work is to evaluate several of the most famous Czech influencers who work on the social platform Instagram. For this purpose, the following research questions were formulated:

RQ1: How many\% of followers actively respond to the influencer's contributions using "likes?"

RQ2: How many\% of followers actively respond to the influencer's contributions using "comments"?

RQ3: How many\% of posts are from 2020?

\section{Literature research}

The main goal of the company management is set up on earnings management, but in the fact, sometimes are earnings deliberately overrated (Klieštik et al. 2020). Management has many ways to fill financial expectations. On of them is psychological influence via online social media (Nica, Gajanová and Kicová, 2019) or classic outdoor advertising (Zahrádka, Machová and Kučera, 2021). These methods are aimed on customers and finally at company performance, which is illustrated in sales (Vochozka, Rowland and Vrbka, 2016).

Influencer marketing represents a 10 billion USD industry in 2020 and is gaining in importance for many companies, especially those operating in a business-to-consumer environment. Several companies in the fashion, cosmetics, travel, food or beverage industries today run marketing campaigns that do not, at least in part, involve working with popular users on platforms such as Instagram and TikTok. However, many marketing managers still do not have sufficient knowledge of these platforms compared to their knowledge of more traditional media channels, and in this rapidly evolving environment, it is often difficult to make the right decision (Haenlein et al. 2020). The visual grasp of what a person represents is an increasingly important element for social media generation. This is especially true for fashion bloggers and "influencers" who make a living - or try to make a living - from their blogs or Instagram accounts. Creating a specific visual universe on these platforms seems to be a common and fundamental practice among these content producers (Eitzinger, 2019).

The influencer marketing literature has identified influencer opinion leadership and a para-social relationship with influencers as two central constructs influencing the shopping intentions of their followers; nevertheless, they are studied only in isolation. The results point to the importance of the social aspect of influencer marketing and inform influencer research and practice about "who says what" to improve communication efficiency (Farivar, Wang and Yuan, 2021). Based on the influencer literature, we argue that each influencer post (consisting of textual and visual information) is an example of stories in which there are main characters and storylines. To uncover the content strategies used by influential social media, we adopted the combined use of machine learning-based topic analysis and deep-learning image analysis to examine the content of captions and photographs contained in influencers' posts on Instagram. The results provided empirical information regarding the use of compelling stories by influencers (Feng, Chen and Kong, 2020).

In the US, Instagram was the best-rated platform for sharing information. Accounts should focus on one area or market, consistent and personal voice, and regular communication (new content at least three times a week) (Stock, 2020). One study sought to identify the keys to creating content and managing a social network that helps explain the results obtained by an influencer. Through a content analysis in the first half of 2019, which consisted of the publication of 164 activity reports on their account, it was found that adapting the language to the network algorithms, visualizing information with infographics and video, using references to popular culture and constructing a story with good and bad characters are some of the characteristics (Marauri-Castillo et al. 2021). Celebrities who use Instagram can influence their followers in many ways, such as influencing their perception of body image, adopting a healthy lifestyle, and persuading them to buy products or services supported by these celebrities (Shariffadeen and Manaf, 2019).

Social media usually relies on two types of accounts: official brand accounts and influencer accounts. The current study examines the relevant mechanisms that explain the effectiveness of Instagram posts in terms of account types (brand accounts on Instagram versus influencer accounts on Instagram) and content types. The survey found that Instagram posts promoted by influencers would have similar effects and social presence, even if they do not appear in branded content themselves. This research contributes to the understanding of effective predecessors of credibility in fashion marketing and the management of fashion brands based on social media. The types 
of accounts and types of content on Instagram influence the extent to which communication on social media enables the creation of emotional bonds and the positive evaluation of a fashion brand (Jin, Ryu and Muqaddam, 2021).

Tafesse and Wood (2021) examine how content and strategies with influencer involvement on Instagram are measured both individually and interactively (i.e., number of followers, number of people following, volume of content, and domains of interest). The study uses unique Instagram influencer data to test its hypotheses. The findings suggest that the number of followers and the volume of content are negatively linked to the involvement of followers, while the number of accounts the influencer is following is positively linked to the involvement of followers. However, these main effects are modified by the influencer domains of interest. The findings contribute to the literature by shedding light on how elements of influencer content and strategies contribute to Instagram follower engagement. Weismuelleler et al. (2020) examines the impact of influencers' recommendations on social media on purchase intent, more specifically the impact of advertising and the credibility of the source in this process. The proposed framework argues that the publication of advertising has a significant impact on the form of sources of credibility, attractiveness and professionalism; partial dimensions that positively affect the consumer's purchasing intention. Empirical evidence based on 306 German Instagram users aged 18 to 34 reveals that the attractiveness of the source, the credibility of the source and the expertise of the source significantly increase the consumer's purchase intention; while the publication of an advertisement indirectly affects the intention of the consumer to purchase by affecting the attractiveness of the source. The results also show that the number of followers positively affects the attractiveness of the source, the credibility of the source and the purchase intention. Overall, this paper contributes uniquely to the product promotion literature, with evidence highlighting how influential social media and Instagram advertising can be used to effectively increase consumer purchase intent.

Most studies on influencer marketing techniques have focused on promoting unhealthy foods, while little is known about promoting healthier foods. This experimental study examined whether a real influencer versus a fictitious influencer is more successful in promoting healthy food products. In addition, we examined the role of para-social interaction as the basic mechanism for approving healthy foods. The results showed that the para-social interaction mediated the relationship between the type of influencer and the attitude to the product, as well as the purchase intention. Para-social interaction was higher in participants who were exposed to the popular real influencer compared to the fictitious influencer, which led to a higher prestige perception of the health food brand and the purchase intention of their followers in successfully promoting a healthy product. We suggest that the promotion of healthy foods could be more successful in the field of public health using popular influencers (Folkvord, Roes and Bevelander, 2020).

Perez (2019) analyze the copyright implications of using copyrighted content on Instagram "stories" as part of the Social Media Influencer (SMI) approval activities in the light of Colombian law. Social media brought an economic revolution, where SMIs found a way to make a living by producing advertising content on their social media accounts. Some of the key interactions used by these influencers come in the form of "Stories" used on the popular "Instagram" social media platform: posts in the form of photos and videos that constantly use copyrighted content and third-party copyrights. Overall, the Colombian copyright jurisdiction complies with the standard of protection set by international treaties with regard to the digital use of copyrighted works, such as those created in Instagram stories. However, the uncertainty of some provisions of the law could cause problems in interpreting these uses.

In order to achieve a deeper understanding of communication and sustainable tourism in urban and rural areas through the "eyes of users", the contribution identifies the different types of influencers on Instagram, and how they are linked to tourist destinations. From January 2012 to January 2019, social media focusing on the role of influencers in shaping the view of destinations analyzes posts using the hashtag \#sustainabletourism. An approach based on a mixed method related to the content and typology of influencers was used to map the development of sustainable tourism. The results show that different types of influencers on Instagram generate involvement differently according to tourist destinations (Palazzo et al. 2021).

\section{Data and methods}

The base source of data will be the data from individual Instagram profiles, which we will analyze using classification analysis. For this research, we will leave the selection of Instagram profiles up to the respondents, to whom we will send a google questionnaire created in advance. The questionnaire will ask the following questions (Q):

\section{Q1: Do you actively use the social platform Instagram?}

Q2: Do you think "influencer" is a real job to be able to make a living from?

\section{Q3: Are you impressionable by influencers?}

Q4: According to what criteria do you choose influencers?

Q5: Which influencers, out of the 20 below, are you actively following?

The questionnaire will be set so that if the respondent answers "no" in Q1, the questionnaire will be closed for him, thus preventing false information. If the respondent states "yes" in Q1, he/she will continue the following questions. In Q5, individual pseudonyms of influencers will be listed, where respondents will choose which of them they actively follow. Based on the answers from Q5, we will select the 7 most followed influencers (according to the respondents) and then we will obtain data, which will be used to find answers to the research questions set out in the introduction.

The analysis itself will consist of the creation of tables, in which we will then record the data obtained from individual Instagram profiles. The data will relate to the number of followers, the total posts submitted during the existence of the Instagram profile, the number of posts submitted in 2020, the number of likes and comments for the last five posts. Subsequently, these data will be analyzed using an arithmetic mean and then expressed as a percentage.

In our analysis we will work with real influencers, therefore they will be further marked by placeholders (I1, I2, I3..., In).

\section{Results}

In the tables below (Tab. 1, Tab. 2, Tab. 3) individual data on selected influencers were presented, the analysis of which led to the answer to the research questions mentioned in the introduction, based on their last five posts as of April 3rd, 2021. As already mentioned in the methodology, influencers were selected with the help of respondents. However, according to Tab. 1 it is clear that the numbers of their followers are somewhat different, so there is a range of different categories of influencers, according to the number of followers. Individual Instagram profiles were established within the range of 20182019. 
Tab. 1: general influencer data

\begin{tabular}{|c|c|c|c|c|}
\hline Influencer & $\begin{array}{c}\text { Number of } \\
\text { followers }\end{array}$ & $\begin{array}{c}\text { Total } \\
\text { posts }\end{array}$ & $\begin{array}{c}\text { Posts from } \\
\mathbf{2 0 2 0}\end{array}$ & $\begin{array}{c}\text { Posts from } \\
\mathbf{2 0 2 0} \text { (\%) }\end{array}$ \\
\hline I1 & 310,000 & 1,057 & 409 & $3 \mathbf{3 9 \%}$ \\
\hline I2 & 211,000 & 789 & 462 & $\mathbf{5 9 \%}$ \\
\hline I3 & 390,000 & 860 & 356 & $\mathbf{4 1 \%}$ \\
\hline I4 & 532,000 & 1,541 & 299 & $\mathbf{1 9 \%}$ \\
\hline I5 & 630,000 & 964 & 464 & $\mathbf{4 8 \%}$ \\
\hline I6 & 628,000 & 2,553 & 703 & $\mathbf{2 8 \%}$ \\
\hline I7 & 515,000 & 3,536 & 314 & $\mathbf{9 \%}$ \\
\hline
\end{tabular}

Source: instagram.com (2021), own interpretation.

It is clear from the table (Tab. 1) that different influencers have very different data. At the same time, Tab. 1 shows the percentage of posts added in 2020. The data show that even though, for example, I7 has 515,000 followers and ranks 4th in this table, their posts from 2020 make up only $9 \%$ of all posts. In contrast, I2 has the lowest number of followers of the selected influencers and their posts from 2020 account for 59\%. If we compare these two influencers (I7, I2), it is obvious that everything depends only on the personality of the influencer and their approach to individual posts.

Tab. 2: "like" statistics

\begin{tabular}{|c|c|c|c|}
\hline Influencer & $\begin{array}{l}\text { Individual } \\
\text { "likes" on the } \\
\text { last } 5 \text { posts }\end{array}$ & $\begin{array}{l}\text { Average } \\
\text { number of } \\
\text { "likes" on the } \\
\text { last } 5 \text { posts }\end{array}$ & $\begin{array}{c}\text { Active responders } \\
\text { - "like" }\end{array}$ \\
\hline I1 & 30,871 & \multirow{5}{*}{$15,538.75$} & \multirow{5}{*}{$5 \%$} \\
\hline & 21,869 & & \\
\hline & 18,658 & & \\
\hline & 15,298 & & \\
\hline & 6,330 & & \\
\hline \multirow[t]{5}{*}{ I2 } & 12,562 & \multirow{5}{*}{$18,313.75$} & \multirow{5}{*}{$9 \%$} \\
\hline & 20,570 & & \\
\hline & 23,644 & & \\
\hline & 12,328 & & \\
\hline & 16,713 & & \\
\hline \multirow[t]{5}{*}{ I3 } & 12,253 & \multirow{5}{*}{$24,240.25$} & \multirow{5}{*}{$6 \%$} \\
\hline & 18,336 & & \\
\hline & 28,734 & & \\
\hline & 12,849 & & \\
\hline & 37,042 & & \\
\hline \multirow[t]{5}{*}{ I4 } & 27,255 & \multirow{5}{*}{42,248} & \multirow{5}{*}{$8 \%$} \\
\hline & 31,768 & & \\
\hline & 20,233 & & \\
\hline & 66,876 & & \\
\hline & 50,115 & & \\
\hline \multirow[t]{5}{*}{ I5 } & 50,915 & \multirow{5}{*}{$44,902.75$} & \multirow{5}{*}{$7 \%$} \\
\hline & 69,098 & & \\
\hline & 36,264 & & \\
\hline & 38,071 & & \\
\hline & 36,178 & & \\
\hline \multirow[t]{5}{*}{ I6 } & 11,199 & \multirow{5}{*}{$38,762.50$} & \multirow{5}{*}{$6 \%$} \\
\hline & 23,028 & & \\
\hline & 38,691 & & \\
\hline & 47,508 & & \\
\hline & 45,823 & & \\
\hline \multirow[t]{5}{*}{ I7 } & 8,806 & \multirow{5}{*}{$7,942.75$} & \multirow{5}{*}{$2 \%$} \\
\hline & 6,708 & & \\
\hline & 11,113 & & \\
\hline & 7,076 & & \\
\hline & 6,874 & & \\
\hline
\end{tabular}

Source: instagram.com (2021), own interpretation.
From the following table (Tab. 2) we can see how many "likes" the individual influencers have on the last five posts, their averages and the subsequent expression in percentages with respect to the number of followers. From these data (Tab. 2) it is clear that "likes" are actually only given by a minimal number of followers. However, if we were to compare the data obtained, since I3 has 238,000 fewer followers, their percentage of "likes" compared to number of followers is the same.

Tab. 3: "comments" statistics

\begin{tabular}{|c|c|c|c|}
\hline Influencer & $\begin{array}{l}\text { Individual } \\
\text { "comments" on the } \\
\text { last } 5 \text { posts }\end{array}$ & $\begin{array}{c}\text { Average number } \\
\text { of "comments" } \\
\text { on the last } 5 \\
\text { posts }\end{array}$ & $\begin{array}{l}\text { Active } \\
\text { responders - } \\
\text { "comments" }\end{array}$ \\
\hline I1 & 1,748 & \multirow{5}{*}{513} & \multirow{5}{*}{$0.17 \%$} \\
\hline & 365 & & \\
\hline & 166 & & \\
\hline & 198 & & \\
\hline & 90 & & \\
\hline \multirow[t]{5}{*}{ I2 } & 36 & \multirow{5}{*}{63.8} & \multirow{5}{*}{$0.03 \%$} \\
\hline & 76 & & \\
\hline & 79 & & \\
\hline & 94 & & \\
\hline & 34 & & \\
\hline \multirow[t]{5}{*}{ I3 } & 63 & \multirow{5}{*}{52.8} & \multirow{5}{*}{$0.01 \%$} \\
\hline & 35 & & \\
\hline & 67 & & \\
\hline & 75 & & \\
\hline & 24 & & \\
\hline \multirow[t]{5}{*}{14} & 62 & \multirow{5}{*}{66.4} & \multirow{5}{*}{$0.01 \%$} \\
\hline & 84 & & \\
\hline & 95 & & \\
\hline & 35 & & \\
\hline & 56 & & \\
\hline \multirow[t]{5}{*}{ I5 } & 73 & \multirow{5}{*}{66.6} & \multirow{5}{*}{$0.01 \%$} \\
\hline & 64 & & \\
\hline & 85 & & \\
\hline & 38 & & \\
\hline & 73 & & \\
\hline \multirow[t]{5}{*}{ I6 } & 48 & \multirow{5}{*}{45.2} & \multirow{5}{*}{$0.01 \%$} \\
\hline & 42 & & \\
\hline & 78 & & \\
\hline & 26 & & \\
\hline & 32 & & \\
\hline \multirow[t]{5}{*}{ I7 } & 73 & \multirow{5}{*}{56.8} & \multirow{5}{*}{$0.01 \%$} \\
\hline & 46 & & \\
\hline & 62 & & \\
\hline & 24 & & \\
\hline & 79 & & \\
\hline
\end{tabular}

Source: instagram.com (2021), own interpretation.

From the table (Tab. 3) we can see how many "comments" the individual influencers have on the last five posts, their averages and the subsequent expression in percentages with respect to the number of followers. From Tab. 3, or rather from the percentual expression, it is clear that the "comments" below the posts are not very popular among followers. With regard to the number of followers, the value of comments did not exceed $1 \%$ for the 5 monitored posts.

Based on the presented data results, very different values of comments, likes, etc. were found. The results show that followers are often only inspired by the influencer, but only a small percentage of followers actively participate in the reactions to the published posts. 


\section{Discussion}

It is evident that each influencer has a similar composition of their followers, which consists of:

a) their admirers,

b) their haters - followers who do not like them very much, but watch them out of interest/curiosity,

c) others - followers who are neither their admirers nor their haters.

Based on this, all data that are freely available on their individual Instagram profiles were presented, it should also be noted again that in this work, influencers were evaluated on the basis of their last five posts as of April 3, 202. If the analysis was done on a different date, the results will most likely be somewhat different, precisely because the influencers or statistics of their profiles are constantly growing in most cases.

Based on the obtained results, it is now possible to answer the research questions that were formulated for this purpose:

So how many\% of followers actively respond to the influencer's contributions using "likes"? As was evident in the results, the data for each influencer are somewhat different. However, if we were to evaluate the results as a whole, the activity of followers in the area of "likes" ranges from $2 \%$ to $9 \%$ with respect to the total number of their followers.

So how many\% of followers actively respond to the influencer's contributions with "comments"? This RQ2 is very closely related to RQ1, it is a very similar case with the difference that it is not an activity of "likes", but "comments". However, it was found that none of the monitored influencers recorded activity higher than $1 \%$ on the monitored posts in relation to the total number of their followers. The results show that the number of followers an influencer has is not so important, because the activity of "comments" is at the same level for everyone. However, if the influencers would like to record a higher incidence of comments under their posts, there is one fairly simple method, which is to create a post with any kind of contest, where they will require several conditions to participate, one of which will be, for example, to write "done" in the comments; in this case the comment statistics will increase very quickly.

What is the percentage of posts from 2020? In the case of this research question, the data range from $9 \%$ to $59 \%$. Only one thing is evident from this; in the case of the activity of "likes" or "comments" the final data did not differ too much between individual influencers, or it did only slightly, but in the case of the percentage of posts in 2020 the resulting data are very different. As already mentioned in the results, it all depends on the personality of the influencer and their approach. Again, I consider it important to look at Tab. 1, where I2 has the lowest number of followers of the selected influencers and their posts from 2020 make up 59\% of their total Instagram profile. Given that all Instagram profiles were established during the same year, it can be assumed that influencer activity could be somewhat similar, therefore this number is admirable.

Tafesse and Wood (2021) explored how content and strategies are measured with the involvement of influencers on Instagram (i.e., number of followers, number of people following, volume of content, and domains of interest), in regard to which I somewhat identify with them. Shariffadeen and Manaf (2019) argue that celebrities who use Instagram can influence their followers in many ways, and although this claim was made two years ago and still cannot be disagreed with.

There are a lot of questions about the topic of influencers, which is very broad. It would be very interesting to see the resulting data if this analysis was not carried out with only five posts, but with, for example, all that are available on the individual profiles. This topic can be analyzed from several directions, so in our opinion, a deeper examination is necessary.

\section{Conclusion}

The aim of the work was to analyze the communication of an influencer on the social network Instagram. The goal was met by means of classification analysis and subsequent evaluation of the results.

In the results chapter, the data were expressed in a table and then the percentual expression of "success" of a given influencer was calculated, in terms of the amount in which their followers respond to their posts using "likes" or "comments". The results were obtained on the basis of statistics from the last five posts of each influencer on the given date. It is obvious that if we did the same analysis on another day, the results will most likely be somewhat different, due to the fact that this concerns communication through a social network, where the activity is growing each day.

The results obtained inevitably lead to several questions, what would the results be if the analysis was based on posts throughout an entire year? How is it possible that influencer $\mathrm{x}$, which has a lower number of followers, has more activity under their posts than an influencer, which has several times more followers? What is then the real basis of success of a given influencer? Based on the data collected for this research, it is not possible to answer these questions correctly at this time, but the last-mentioned question is worth noting, i.e., what is the real basis of success of a given influencer. Opinions may differ, but as has already been stated, it is probably more about the attitude of each influencer, the quality of their posts and communication towards their followers. However, as mentioned, it is only a probability statement, for a more definite specification of a successful influencer and the answer to these questions, it is necessary to conduct further, follow-up research that will answer the questions and identify this issue more accurately. Subsequently, these research papers will help to better understand the success of an influencer itself.

\section{Literature:}

1. Abdullah, T., Deraman, S. N. S., Zainuddin, S. A., Azmi, N. F., Abdullah, S. S., Anuar, N. I. M., Mohamad, S. R., Zulkiffli, W. F. W., Hashim, N. A. A. N., Abdullah, A. R., Rasdi, A. L. M., Hasan, H.: Impact of social media influencer on instagram user purchase intention towards the fashion products: the perspectives of students. European Journal of Molecular \& Clinical Medicine. 2020, 7(8), 2589-1598 p. ISSN 2515-8260.

2. Balaban, D., Iancu, I. R., Musț̣ea, M., Pavelea, A., Culic, L.: What determines young people to follow influencers? The role of perceived information quality and trustworthiness on users' following intentions. Romanian Journal of Communication and Public Relations. 2020, 22(3), 5-19 p. ISSN 1454-8100.

3. Bessarab. A., Mitchuk, O., Baranetska, A., Kodatska, N., Kvasnytsia, O., Mykytiv, G.: Social networks as a phenomenon of the information society. Journal of Optimization in Industrial Engineering. 2021, 14(1), 35-42 p. ISSN 2251-9904.

4. Eitzinger, M.: "Because I need to create my own universe" bloggers on Instagram and the creation of a digital photomimetic self. Visual Ethnography. 2019, 8(2), 55-71 p. ISSN 2281-1605. 5. Farivar, S., Wang, F., Yuan, Y. F.: Opinion leadership vs. para-social relationship: key factors in influencer marketing, Journal of Retailing and Consumer Services. 2021, 59. ISSN 0969-6989.

6. Feng, Y., Chen, H., Kong, Q.: An expert with whom I can identify: the role of narratives in influencer marketing. International Journal of Advertising. 2020, 40(7), 972-993 p. ISSN 0265-0487.

7. Folkvord, F., Roes, E., Bevelander, K.: Promoting healthy foods in the new digital era on Instagram: an experimental study on the effect of a popular real versus fictitious fit influencer on brand attitude and purchase intentions. BMC Public Health. 2020, 20(1). ISSN 1471-2458.

8. Haenlein, M., Anadol, E., Farnsworth, T., Hugo, H., Hunichen, J., Welte, D.: Navigating the new era of influencer marketing: how to be successful on Instagram, TikTok, \& 
Co. California Management Review. 2020, 63(1), 5-25 p. ISSN 0008-1256.

9. Instagram.com [online] 2021. Available at: https://www.inst agram.com/

10. Jin, S. V., Ryu, E., Muqaddam, A.: I trust what she's \#endorsing on Instagram: moderating effects of parasocial interaction and social presence in fashion influencer marketing. Journal of Fashion Marketing and Management: An International Journal. 2021, 25(4), 665-681 p. ISSN 1361-2026. 11. Klieštik T., Nica, E., Šuleř, P., Valášková, K.: Innovations in the company's earnings management: the case for the Czech Republic and Slovakia. Marketing and Management of Innovations. 3, 332-345 p. ISSN 2218-4511.

12. Lee, S., Kim, E.: Influencer marketing on Instagram: how sponsorship disclosure, influencer credibility, and brand credibility impact the effectiveness of Instagram promotional post. Journal of Global Fashion Marketing. 2020, 11(3), 232249 p. ISSN 2093-2685.

13. Marauri-Castillo, I., Rodríguez-González, M. D., ArmentiaVizuete, I., Marín-Murillo, F.: Estrategia exitosa de información sobre alimentación dirigida a 'millennials': el caso de Carlos Ríos en Instagram. Revista Mediterránea de Comunicación. 2021, 12(1), 253-267 p. ISSN 1989-872X.

14. Martínez-Sanz, R., Gónzález Fernández, C.: Brand communication on Instagram, a gender issue? The role of the fashion influencer. Masculinities \& Social Change. 2018, 7(3), 230-254 p. ISSN 2014-3605.

15. Nadányiová, M., Subhankar, D.: Millennials as a target segment of socially responsible communication within the business stratégy. Littera Scripta. 2020, 13(1), 119-134 p. ISSN 1805-9112.

16. Nica, E., Gajanová, L., Kicová, E.: Customer segmentation based on psychographic and demographic aspects as a determinant of customer targeting in the online environment. Littera Scripta. 12(2), 108-126 p. ISSN 1805-9112.

17. Palazzo, M., Vollero, A., Vitale, P., Siano, A.: Urban and rural destinations on Instagram: exploring the influencers' role in \#sustainabletourism. Land Use Policy. 2021, 100, ISSN 02648377.

18. Perez, M.: Stories of a social media influencer: analysis of the implications of uses of creative works on instagram stories in light of colombian copyright law. Revista La Propiedad Inmaterial. 2019, 27, 149-181 p. ISSN 1657-1959.

19. Shariffadeen, T. S. A. T. M. A., Manaf, A.: Celebrity-fan engagement on Instagram and its influence on the perception of hijab culture among Muslim women in Malaysia. Jurnal Komunikasi-Malaysian Journal of Communication. 2019, 35(1), 286-302 p. ISSN 2289-1528.

20. Stock, M.: High impact extension programming with Instagram. Horttechnology. 2020, 30(6), 654-658 p. ISSN 10630198.

21. Tafesse, W., Wood, B. P.: Followers' engagement with Instagram influencers: the role of influencers' content and engagement strategy. Journal of Retailing and Consumer Services. 2021, 58, ISSN 0969-6989.

22. Vochozka, M., Rowland, Z., Vrbka, J.: Financial analysis of an average transport company in the Czech Republic. Nase More. 63(3), 227-236 p. ISSN 0469-6255.

23. Weismueller, J., Harrigan, P., Wang, S. S., Soutar, G. N.: Influencer endorsements: how advertising disclosure and source credibility affect consumer purchase intention on social media. Australasian Marketing Journal. 2020, 28(4), 160-170 p. ISSN 1839-3349.

24. Zahrádka, J., Machová, V., Kučera, J.: What is the price of outdoor advertising: a case study of the Czech Republic? Ad Alta-Journal of Interdisciplinary Research. 11(1), 386-391 p. ISSN 1804-7890.

Primary Paper Section: A

Secondary Paper Section: AE, AH 